\title{
Association of vitamin D-binding protein variants with chronic obstructive pulmonary disease: a meta-analysis
}

\author{
Y.L. Wang, H. Kong, W.P. Xie and H. Wang \\ Department of Respiratory Medicine, \\ The First Affiliated Hospital of Nanjing Medical University, Nanjing, China \\ Corresponding author: H. Wang \\ E-mail: hongwang@njmu.edu.cn \\ Genet. Mol. Res. 14 (3): 10774-10785 (2015) \\ Received February 6, 2015 \\ Accepted May 15, 2015 \\ Published September 9, 2015 \\ DOI http://dx.doi.org/10.4238/2015.September.9.16
}

\begin{abstract}
Gene polymorphism of vitamin D-binding protein (VDBP) correlates with chronic obstructive pulmonary disease (COPD), but the results remain inconclusive. We aimed to explore the association between VDBP gene polymorphism and COPD. We searched MEDLINE, Embase, Web of Science, and China National Knowledge Infrastructure for publications addressing the association between VDBP gene polymorphism and COPD. After qualitative evaluation, randomized controlled trials were pooled using either a fixedor a random-effect model depending upon the degree of heterogeneity. Eleven studies with 3144 subjects were included. The genotype groupspecific component $(\mathrm{GC}) * 1 \mathrm{~F}-1 \mathrm{~F}$ was significantly associated with COPD in Asians [odds ratio $(\mathrm{OR})=1.73,95 \%$ confidence interval $(\mathrm{CI})$ $=1.07-2.81, \mathrm{P}=0.03]$, but not in Caucasians $(\mathrm{OR}=1.44,95 \% \mathrm{CI}=$ $0.57-3.66, \mathrm{P}=0.45)$. A protective effect of $\mathrm{GC} * 1 \mathrm{~F}-1 \mathrm{~S}$ was observed in Asians $(\mathrm{OR}=0.70,95 \% \mathrm{CI}=0.55-0.89, \mathrm{P}=0.003)$ but not in Caucasians $(\mathrm{OR}=0.93,95 \% \mathrm{CI}=0.69-1.24, \mathrm{P}=0.61)$. There was no association of GC*1S-1S, GC*2-1S and GC*1F-2 with COPD. As for alleles, $\mathrm{GC}^{*} 1 \mathrm{~F}$ was a risk factor, whereas $\mathrm{GC}^{*} 1 \mathrm{~S}$ was protective against
\end{abstract}


COPD in Asians; GC*2 was not protective. The genotype GC*1F-1F or allele $\mathrm{GC}^{*} 1 \mathrm{~F}$ was associated with increased susceptibility to $\mathrm{COPD}$ in Asians. No protective effect of genotype GC*2-2 against COPD was found. The protective effects of $\mathrm{GC} * 1 \mathrm{~F}-1 \mathrm{~S}$ and $\mathrm{GC} * 1 \mathrm{~S}$ were observed in Asians but not in Caucasians. The VDBP gene polymorphism could be a potential marker for screening of COPD.

Key words: Vitamin D-binding protein; Gene polymorphism; Chronic obstructive pulmonary disease; Meta-analysis

\section{INTRODUCTION}

Chronic obstructive pulmonary disease (COPD), a common preventable and treatable disease, is characterized by persistent airflow limitation that is usually progressive and associated with an enhanced chronic inflammatory response in the airways and the lungs to noxious particles or gases. COPD imposes a heavy economic and social burden because it is among the leading causes of morbidity and mortality. The Global Burden of Disease Study predicted that COPD would become the third most significant cause of death worldwide by 2020 (Mathers and Loncar, 2006). Although cigarette smoking is well recognized as the most important COPD risk factor, only $10-20 \%$ of smokers become clinically symptomatic of COPD (Xue et al., 2012), and nonsmokers may also develop irreversible chronic airflow limitation (Eisner et al., 2010; Lamprecht et al., 2011). In addition, impaired lung function and COPD sometimes appear in familial clustering. Therefore, COPD results from a gene-environment interaction. Some studies have been performed to identify genetic factors of susceptibility to COPD, and several candidate genes have been tested (Bakke et al., 2011).

The existing literature indicates that vitamin D plays an important role in asthma (Devereux et al., 2009), COPD (Jackson and Hopkonson, 2011), and tuberculosis (Rathored et al., 2012). In the circulation, vitamin D has to bind vitamin D-binding protein (VDBP), which is also called group-specific component of serum globulin (Gc-globulin). Meanwhile, VDBP has anti-inflammatory and immunomodulatory functions (Chishimba et al., 2010). The protein can strengthen complement-mediated neutrophil chemotaxis of C5a and C5a des-Arg and activate macrophages at inflammation sites (Laufs et al., 2004). Because neutrophils and macrophages are indispensable for parenchymal destruction and airway inflammation in COPD (Cockayne et al., 2012), Gc-globulin has been recognized as a possible participant in its pathogenesis.

Gc-globulin is a serum $\alpha 2$-globulin with a molecular weight of 52-59 $\mathrm{kDa}$. The human Gc-globulin gene is located on the long arm of chromosome 4 (4q12-q13). Gc-globulin shows genetic variability due to its 3 major polymorphic alleles (GC*1F, GC*1S, and $\left.\mathrm{GC}^{*} 2\right)$ and over 120 rare variant alleles. Single nucleotide polymorphisms (rs4588 and rs7041) in exon 11 of the gene lead to the common isoforms. They are termed GC1 and GC2, whereas GC1 is further subdivided into $\mathrm{GC} * 1 \mathrm{~F}$ and $\mathrm{GC}^{*} 1 \mathrm{~S}$. The protein products are different at positions 416 and 420. At position 416, it is glutamic acid for both $\mathrm{GC}^{*} 1 \mathrm{~S}$ and $\mathrm{GC} * 2$, while it is aspartic acid for $\mathrm{GC}^{*} 1 \mathrm{~F}$. At position 420 , it is threonine for both $\mathrm{GC}^{*} 1 \mathrm{~F}$ and $\mathrm{GC} * 1 \mathrm{~S}$, while it is lysine for $\mathrm{GC}^{* 2}$. There are 6 genotypes, including $\mathrm{GC}^{*} 1 \mathrm{~F}-1 \mathrm{~F}, \mathrm{GC}^{*} 1 \mathrm{~S}-1 \mathrm{~S}$, and $\mathrm{GC}^{*} 2-2$ homozygotes, and $\mathrm{GC} * 1 \mathrm{~F}-1 \mathrm{~S}, \mathrm{GC} * 2-1 \mathrm{~F}$, and $\mathrm{GC} * 2-1 \mathrm{~S}$ heterozygotes.

Although some studies have reported an association between this genetic variation and COPD, the conclusions are controversial (Kueppers et al., 1977; Kauffmann et al., 1983; 
Horne et al., 1990; Schellenberg et al., 1998). Therefore, we conducted a meta-analysis of the published studies to ascertain the relationship between the polymorphisms of Gc-globulin and COPD.

\section{MATERIAL AND METHODS}

\section{Publication search}

A literature search from 1990 to 2014 was performed in the electronic databases PubMed, Web of Science, and China National Knowledge Infrastructure (CNKI). The search terms were "vitamin D binding protein", "group-specific component", "Gc-globulin", "Chronic obstructive pulmonary disease", and "COPD", The search was restricted to English and Chinese, and the last search took place in December 2014. The selected studies had to conform to the following major criteria: 1) they were independent case-control studies on humans; 2) they analyzed the influence of Gc gene polymorphisms on COPD risk; 3) they provided individual genotype numbers in COPD cases and controls.

\section{Data extraction}

The data were extracted from each study independently by 2 investigators. Any disagreements were resolved through the third party, and the final inclusion was decided by our research team. The data were recorded as follows: first author's name, publication year, country, ethnicity, number of genotypes, matching criteria, and total numbers of case patients and control subjects.

\section{Statistical analysis}

Meta-analysis was performed in Review Manager 5.3 (Cochrane Collaboration). The association of the Gc gene polymorphism with COPD was analyzed using odds ratios (ORs) with a $95 \%$ confidence interval (CI). The studies were confirmed to satisfy the Hardy-Weinberg equilibrium. The percentage of between-study heterogeneity was calculated by the $\mathrm{I}^{2}$ test and $\chi^{2}$-based Q analysis. Heterogeneity was considered high when the $\mathrm{I}^{2}$ value was greater than $50 \%$. Heterogeneity was considered to be statistically significant when the $\mathrm{P}$ value was smaller than 0.05 for the Q analysis; therefore, a random-effect model was applied to calculate the OR. Otherwise, a fixed-effect model was utilized. The Z-test was used to determine the pooled $\mathrm{OR}$, and significance was set to $\mathrm{P}<0.05$. The possible publication bias was evaluated through visual inspection of funnel plots: the Begg test and the Egger asymmetry test.

\section{RESULTS}

\section{Characteristics of the studies selected}

As shown in Figure 1, 75 papers were found through the database searching, and 11 papers reporting 12 trials were finally eligible for inclusion. The characteristics of these 12 trials including 7 on Asians and 5 on Caucasians are shown in Table 1. Among the 12 trials, 2 trials indicated that $\mathrm{GC} * 1 \mathrm{~F}-1 \mathrm{~F}$ increased the risk of COPD while $\mathrm{GC} * 2-2$ exerted a protective effect; 4 trials showed that $\mathrm{GC}^{*} 1 \mathrm{~F}-1 \mathrm{~F}$ increased the risk of COPD and no protective effect 
was observed; 3 trials indicated that $\mathrm{GC}^{*} 1 \mathrm{~F}-2$ was a risk factor whereas 1 of 3 trials indicated that $\mathrm{GC}^{*} 1 \mathrm{~F}-1 \mathrm{~S}$ was a protective genotype; 1 trial indicated that $\mathrm{GC}^{*} 1 \mathrm{~S}-1 \mathrm{~S}$ was a protective genotype, and the other 2 trials identified neither a risk genotype nor a protective genotype. The data were collected from 1485 COPD patients and 1659 controls (Figure 1 and Table 1).

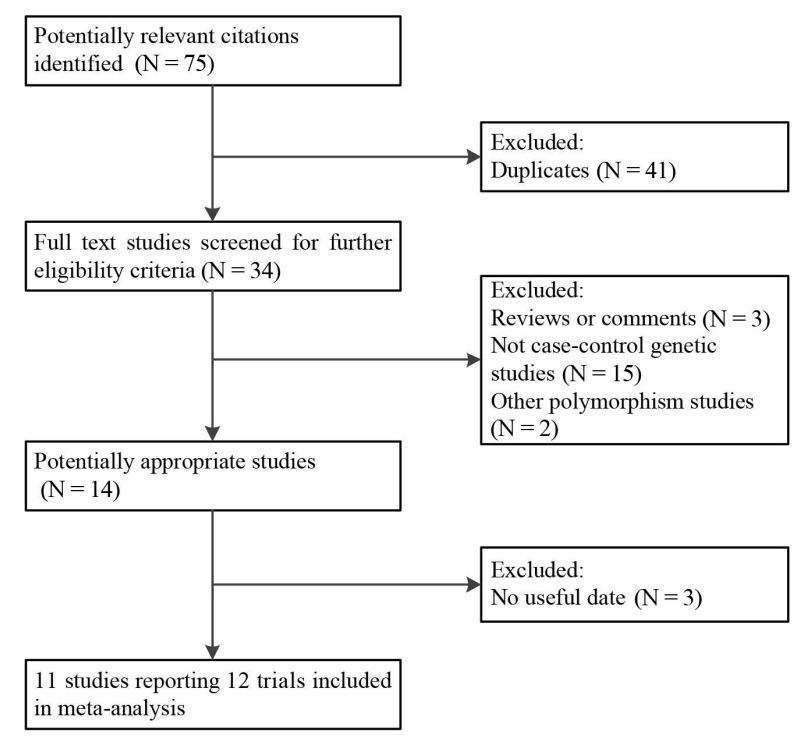

Figure 1. Flow chart of the search process.

Table 1. Main characteristics of the included studies.

\begin{tabular}{lllcll}
\hline First author-year & Country & Ethnicity & No. of cases/controls & Risk genotype & Protective genotype \\
\hline Ishii (2001) & Japan & Asian & $63 / 82$ & GC*1F-1F & - \\
Ito (2004) & Japan & Asian & $103 / 88$ & GC*1F-1F & - \\
Lu (2004) & China & Asian & $69 / 52$ & GC*1F-1F & - \\
Korytina (2006) & Tatar & Asian & $131 / 106$ & GC*1F-2 & GC*1F-1S \\
Shen (2010) & China & Asian & $100 / 100$ & GC*1F-1F & GC*2-2 \\
Li (2014) & China & Asian & $116 / 134$ & GC*1F-2 & - \\
Jung (2014) & Korean & Asian & $203 / 157$ & - & GC*1S-1S \\
Horne (1990) & Canada & Caucasian & $104 / 413$ & GC*1F-1F & - \\
Schellenberg (1998) & Canada & Caucasian & $75 / 64$ & GC*1F-1F & GC*2-2 \\
Laufs (2004) & Iceland & Caucasian & $102 / 183$ & - & - \\
Korytina (2006) & Russia & Caucasian & $166 / 130$ & - & - \\
Janssens (2010) & Belgium & Caucasian & $253 / 150$ & GC*1F-2 & - \\
\hline
\end{tabular}

\section{Association between 6 major genotypes of Gc-globulin and COPD}

Eleven trials were identified, where the genotype $\mathrm{GC} * 1 \mathrm{~F}-1 \mathrm{~F}$ status was determined in COPD patients and controls. Because heterogeneity among studies $\left(\chi^{2}=25.97, \mathrm{P}<0.05, \mathrm{I}^{2}\right.$ $=61 \%$ ) was observed, we used the random-effect model for the meta-analysis. As shown in Figure 2, we observed a significantly increased OR summations over all populations for genotype $\mathrm{GC}^{*} 1 \mathrm{~F}-1 \mathrm{~F}(\mathrm{OR}=1.64,95 \% \mathrm{CI}=1.09-2.48, \mathrm{P}=0.02)$. Significant heterogeneity was also found after stratification by ethnicity (for Asian studies: $\chi^{2}=18.62, \mathrm{P}=0.005, \mathrm{I}^{2}=68 \%$; for 
Caucasian studies: $\left.\chi^{2}=6.70, \mathrm{P}=0.08, \mathrm{I}^{2}=55 \%\right)$. GC*1F-1F was identified as a significant risk factor for COPD in Asians $(\mathrm{OR}=1.73,95 \% \mathrm{CI}=1.07-2.81, \mathrm{P}=0.03)$ but not in Caucasians $(\mathrm{OR}=1.44,95 \% \mathrm{CI}=0.57-3.66, \mathrm{P}=0.45$; Figure 2$)$.

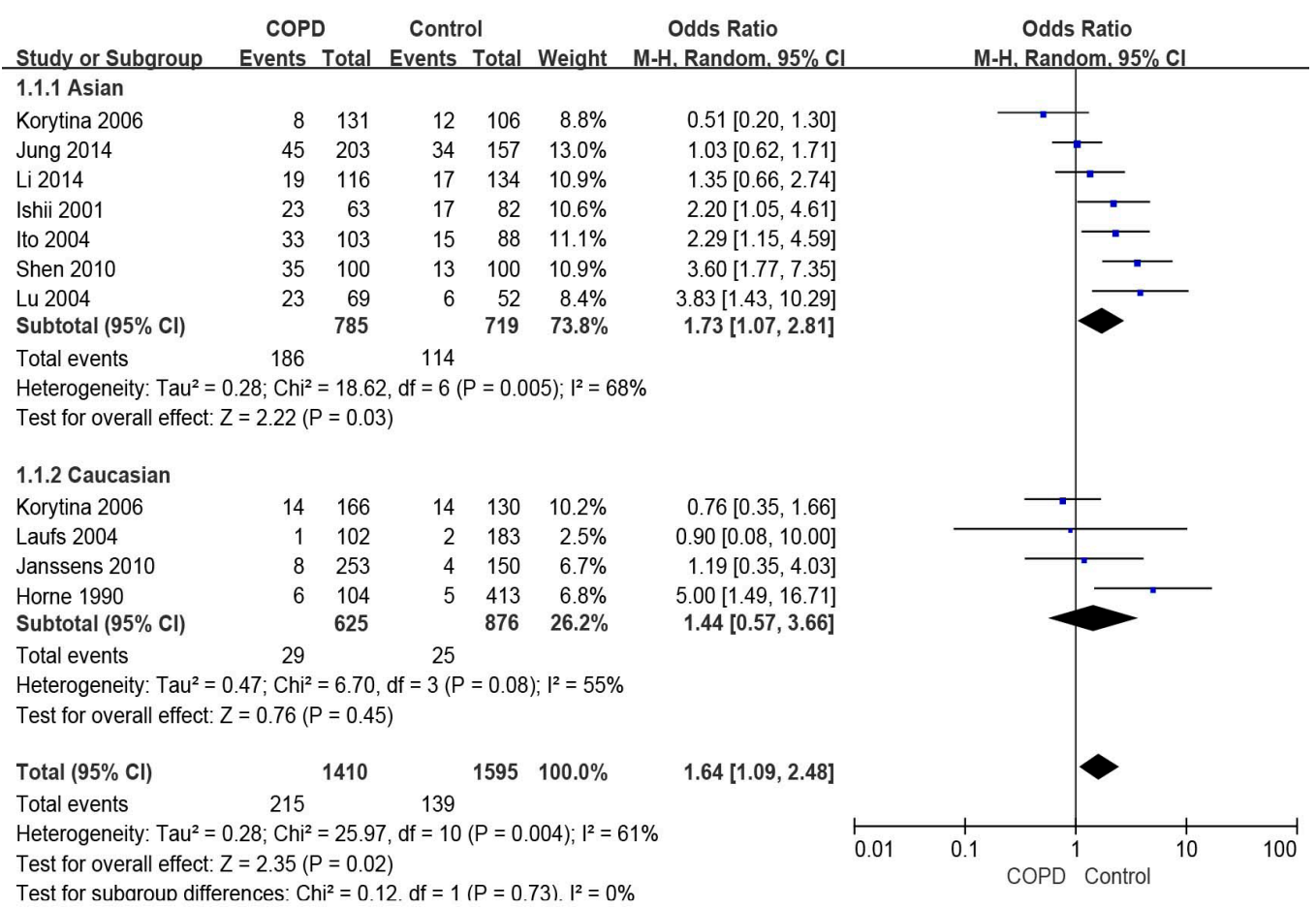

Figure 2. Odds ratios $(\mathrm{OR})$ and $95 \%$ confidence intervals $(\mathrm{CI})$ for genotype $\mathrm{GC} * 1 \mathrm{~F}-1 \mathrm{~F}$ in the comparison of chronic obstructive pulmonary disease (COPD) with control.

The relationship between genotype $\mathrm{GC}^{*} 2-2$ and $\mathrm{COPD}$ is shown in Figure 3. The analysis was conducted using the random-effect model because there was significant heterogeneity among total population studies $\left(\chi^{2}=22.04, \mathrm{P}=0.01, \mathrm{I}^{2}=55 \%\right)$. After the stratification by ethnicity, we conducted the analysis using a random-effect model for Asian studies and a fixed-effect model for Caucasian studies. No significantly protective effect of genotype GC*2-2 against COPD was observed in Asians $(\mathrm{OR}=0.71,95 \% \mathrm{CI}=0.34-1.48, \mathrm{P}=0.36)$ or Caucasians $(\mathrm{OR}=0.83,95 \% \mathrm{CI}=0.56-1.24, \mathrm{P}=0.36$; Figure 3$)$.

Figure 4 shows the results on the association of GC*1F-1S with COPD. The analysis was conducted with the fixed-effect model. A significantly protective effect was observed in Asians $(\mathrm{OR}=0.70,95 \% \mathrm{CI}=0.55-0.89, \mathrm{P}=0.003)$, but not in Caucasians $(\mathrm{OR}=0.93,95 \% \mathrm{CI}$ $=0.69-1.24, \mathrm{P}=0.61$; Figure 4).

As shown in Table 2, no significant association of the 3 other genotypes $\left(\mathrm{GC}^{*} 1 \mathrm{~S}\right.$ $1 \mathrm{~S}$ homozygotes, $\mathrm{GC}^{*} 2-1 \mathrm{~S}$ heterozygotes, and $\mathrm{GC} * 1 \mathrm{~F}-2$ heterozygotes) with $\mathrm{COPD}$ was observed (Table 2). 


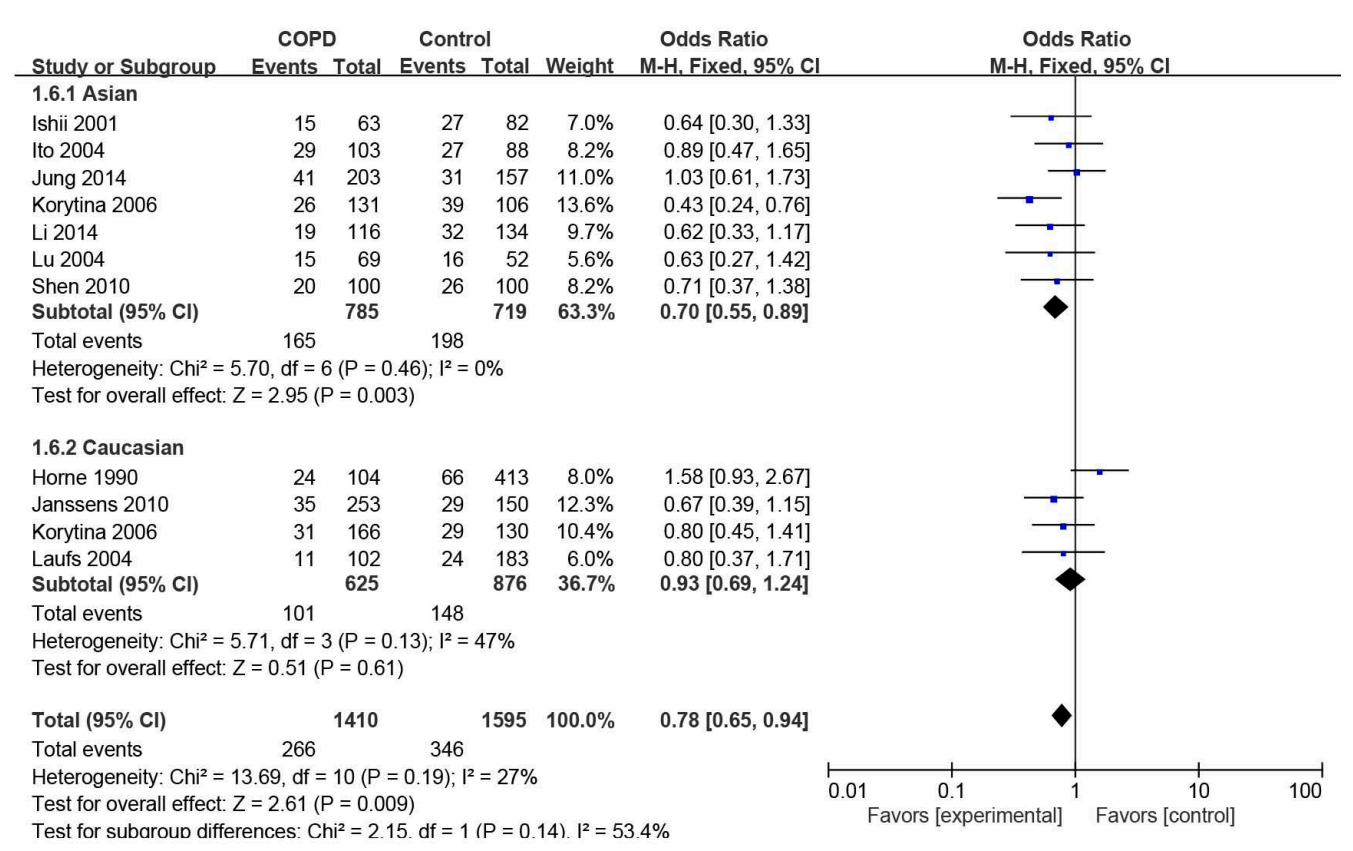

Figure 4. Odds ratios (OR) and $95 \%$ confidence intervals $(\mathrm{CI})$ for genotype GC*1F-1S in the comparison of chronic obstructive pulmonary disease (COPD) with control.

Table 2. Association of the other four genotypes with chronic obstructive pulmonary disease (COPD).

\begin{tabular}{|c|c|c|c|c|c|c|c|c|c|}
\hline \multirow[t]{2}{*}{ Genotype } & \multirow[t]{2}{*}{ Ethnicity } & \multirow{2}{*}{$\begin{array}{c}\text { Case } \\
\mathrm{N}(\%) \\
\end{array}$} & \multirow{2}{*}{$\begin{array}{c}\text { Control } \\
\mathrm{N}(\%) \\
\end{array}$} & \multicolumn{3}{|c|}{ Heterogeneity test (Q-test) } & \multirow[t]{2}{*}{ OR $(95 \% \mathrm{CI})$} & \multicolumn{2}{|c|}{ Pooled OR test (z-test) } \\
\hline & & & & $\chi^{2}$ & $\mathrm{P}$ & $\mathrm{I}^{2}(\%)$ & & $\mathrm{z}$ & $\mathrm{P}$ \\
\hline \multirow[t]{3}{*}{$1 \mathrm{~S}-1 \mathrm{~S}$} & Asian & $63(8.0)$ & $65(9.0)$ & 13.02 & 0.04 & 54 & $0.87(0.60-1.26)$ & $0.67^{\mathrm{a}}$ & 0.50 \\
\hline & Caucasian & $206(32.7)$ & $288(32.9)$ & 1.88 & 0.60 & 0 & $1.10(0.87-1.39)$ & $0.78^{\mathrm{b}}$ & 0.44 \\
\hline & Total & $269(19.1)$ & $353(22.1)$ & 15.83 & 0.10 & 37 & $1.03(0.84-1.25)$ & $0.25^{\mathrm{b}}$ & 0.80 \\
\hline \multirow[t]{3}{*}{$2-1 \mathrm{~S}$} & Asian & $122(15.5)$ & $128(17.8)$ & 1.28 & 0.97 & 0 & $0.83(0.63-1.10)$ & $0.66^{\mathrm{b}}$ & 0.19 \\
\hline & Caucasian & $181(29.0)$ & $289(33.0)$ & 2.76 & 0.43 & 0 & $0.82(0.64-1.04)$ & $1.62^{\mathrm{b}}$ & 0.11 \\
\hline & Total & $303(21.5)$ & $417(26.1)$ & 4.04 & 0.95 & 0 & $0.83(0.69-1.01)$ & $1.69^{\mathrm{b}}$ & 0.05 \\
\hline \multirow[t]{3}{*}{$1 \mathrm{~F}-2$} & Asian & $197(25.1)$ & $156(21.7)$ & 16.04 & 0.01 & 63 & $1.19(0.79-1.80)$ & $0.85^{\mathrm{a}}$ & 0.40 \\
\hline & Caucasian & $63(10.1)$ & $52(5.9)$ & 7.26 & 0.06 & 59 & $1.34(0.63-2.84)$ & $0.71^{\mathrm{a}}$ & 0.48 \\
\hline & Total & $260(18.4)$ & $208(13.0)$ & 10.00 & 0.008 & 58 & $1.24(0.88-1.76)$ & $1.23^{\mathrm{a}}$ & 0.22 \\
\hline
\end{tabular}

${ }^{\mathrm{a} A n a l y z e d}$ with a random-effect model. ${ }^{\mathrm{b}}$ Analyzed with a fixed-effect model.

\section{Association of 3 alleles of Gc-globulin and COPD}

The analysis of the association of allele GC* $1 \mathrm{~F}$ with COPD was based on 11 trials, as shown in Figure 5. Because the heterogeneity test indicated the presence of heterogeneity among the studies $\left(\chi^{2}=25.10, \mathrm{P}=0.005, \mathrm{I}^{2}=60 \%\right)$, the analysis was conducted with a random-effect model. A significantly increased OR summation across all populations for allele $\mathrm{GC}^{*} 1 \mathrm{~F}$ was observed $(\mathrm{OR}=1.27,95 \% \mathrm{CI}=1.04-1.54, \mathrm{P}=0.02)$. After the stratification by ethnicity, a significant risk of COPD associated with allele GC*1F was observed in Asians $(\mathrm{OR}=1.35,95 \% \mathrm{CI}=1.04-1.75, \mathrm{P}=0.02)$ but not in Caucasians $(\mathrm{OR}=1.13,95 \% \mathrm{CI}=0.83$ $1.54, \mathrm{P}=0.43$; Figure 5). 


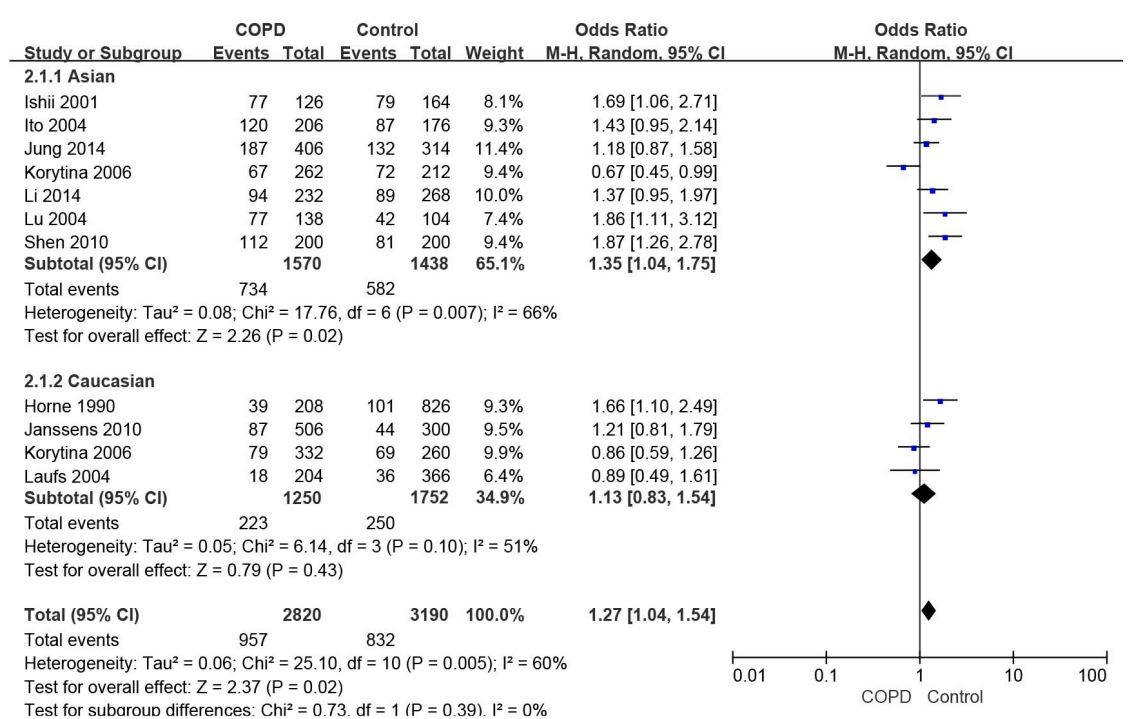

Figure 5. Odds ratios $(\mathrm{OR})$ and $95 \%$ confidence intervals $(\mathrm{CI})$ for the $\mathrm{GC} * 1 \mathrm{~F}$ allele in the comparison of chronic obstructive pulmonary disease (COPD) with control.

Figure 6 provided the results for the association of allele GC*2 with COPD. The analysis was based on the random-effect model because the heterogeneity test showed significant heterogeneity among the studies $\left(\chi^{2}=34.31, \mathrm{P}=0.0003, \mathrm{I}^{2}=68 \%\right)$. No significant protective effect of allele $\mathrm{GC} * 2$ against COPD was observed in Asians $(\mathrm{OR}=0.88,95 \% \mathrm{CI}=0.63-1.24$, $\mathrm{P}=0.47)$ or Caucasians $(\mathrm{OR}=0.90,95 \% \mathrm{CI}=0.69-1.19, \mathrm{P}=0.46$; Figure 6$)$.

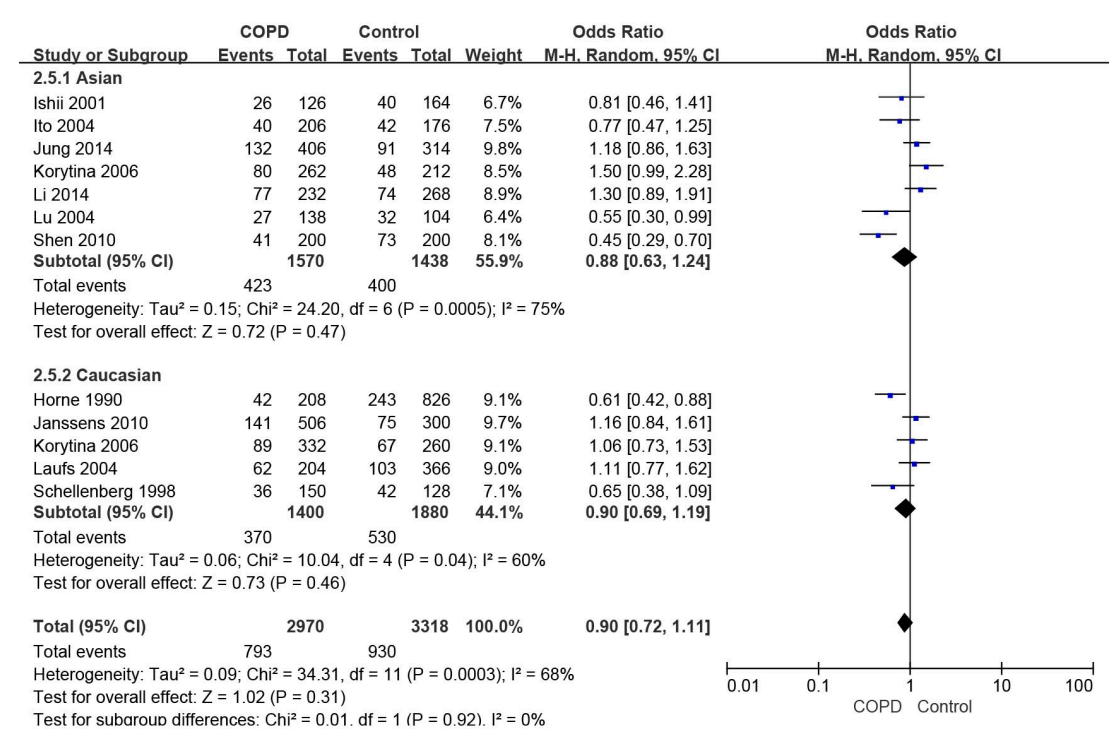

Figure 6. Odds ratios (OR) and $95 \%$ confidence intervals (CI) for the $\mathrm{GC} * 2$ allele in the comparison of chronic obstructive pulmonary disease (COPD) with control. 
The results on the association of allele $\mathrm{GC}^{*} 1 \mathrm{~S}$ with COPD are shown in Figure 7. Because the results of the test for heterogeneity among the studies were insignificant $\left(\chi^{2}=15.32\right.$, $\mathrm{P}=0.12, \mathrm{I}^{2}=35 \%$ ), a fixed-effect model was utilized for the meta-analysis. It showed that allele $\mathrm{GC}^{*} 1 \mathrm{~S}$ exerted a protective effect $(\mathrm{OR}=0.86,95 \% \mathrm{CI}=0.77-0.96, \mathrm{P}=0.007)$. After the stratification by ethnicity, a significantly protective effect of allele $\mathrm{GC} * 1 \mathrm{~S}$ against COPD was observed in Asians $(\mathrm{OR}=0.76,95 \% \mathrm{CI}=0.64-0.89, \mathrm{P}=0.0007)$ but not in Caucasians $(\mathrm{OR}=$ $0.97,95 \% \mathrm{CI}=0.83-1.13, \mathrm{P}=0.67$; Figure 7 ).

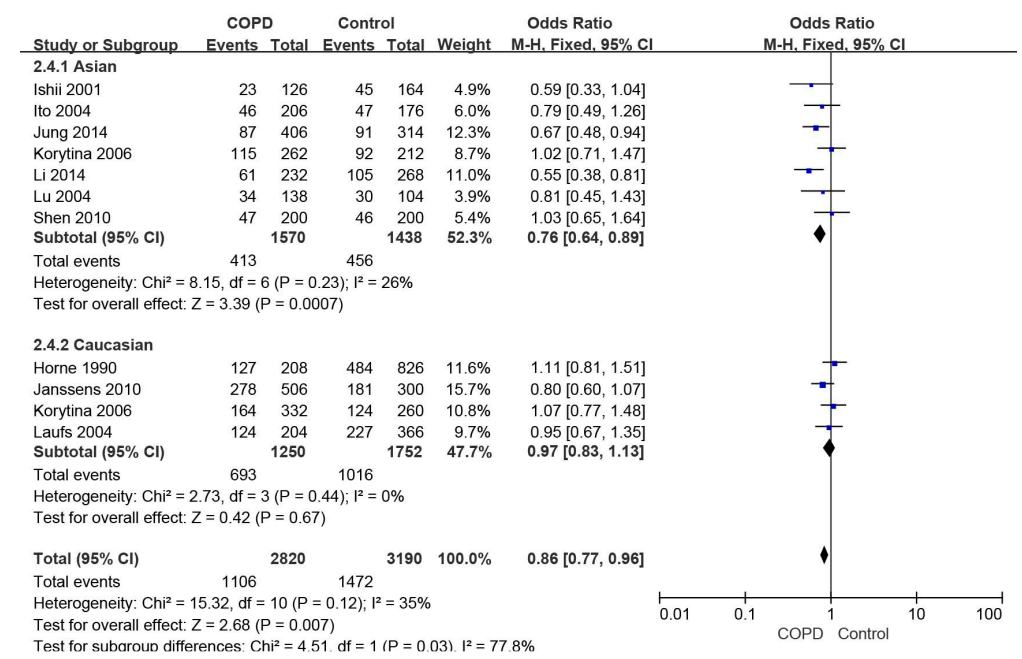

Figure 7. Odds ratios (OR) and $95 \%$ confidence intervals $(\mathrm{CI})$ for the $\mathrm{GC} * 1 \mathrm{~S}$ allele in the comparison of chronic obstructive pulmonary disease (COPD) with control.

\section{Bias diagnostics}

The publication bias was assessed using funnel plot analysis and the Egger test as shown in Figure 8. The funnel plot did not show any evidence of a publication bias.

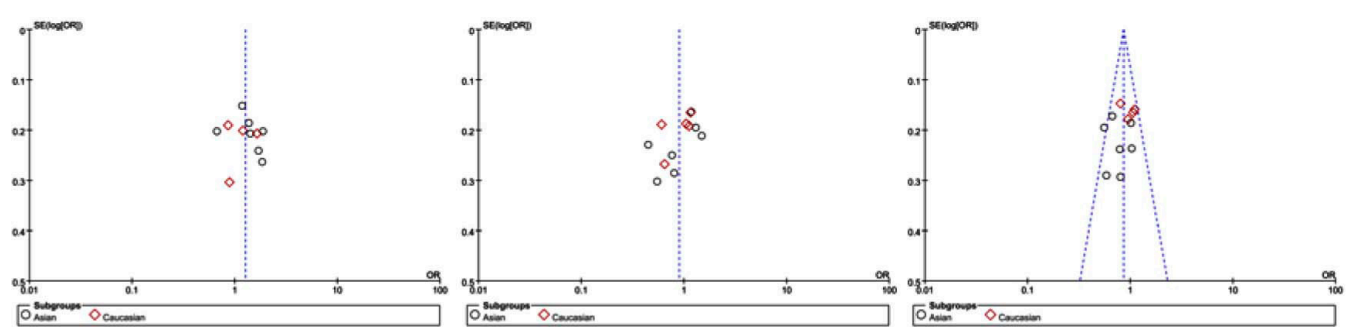

Figure 8. Funnel plot assessing the possible publication bias.

\section{DISCUSSION}

There are 2 major pathophysiological mechanisms of the loss of lung function in COPD. First, the release of extracellular proteases may damage the lung parenchyma, enlarge 
the alveoli, and then cause the emphysema. Second, inflammation of peripheral airways resulting from various factors, e.g., mucous hypersecretion, fibrosis, and edema, may narrow the airways and increase their resistance. Both of these pathophysiological mechanisms reduce the maximal lung expiratory flow. In the 2 processes of COPD, gene products can affect the intensity and consequences of the inflammatory response (Schellenberg et al., 1998).

Persistence of systemic inflammation in COPD is a risk factor for worse clinical outcomes. It results in a higher incidence of exacerbation and worse survival (Agusti et al, 2012). VDBP has 2 important biological functions in the development of inflammation and COPD. First, the protein enhances the chemotactic activity of $\mathrm{C} 5 \mathrm{a}$ and $\mathrm{C} 5 \mathrm{a}$ des-Arg for neutrophils. Second, VDBP may undergo removal of specific glycosylated moieties and get converted into a potent macrophage activating factor (Ito et al., 2004).

Studies on the possible association of the VDBP genotypes and alleles with COPD have produced controversial results. The frequency of homozygotes GC* $1 \mathrm{~F}-1 \mathrm{~F}$ in COPD patients is significantly higher than that in the control group: 6 versus $1 \%$; however, the relative risk is 4.8 (Horne et al., 1990). The allele $\mathrm{GC}^{*} 1 \mathrm{~F}$ contributes to chronic hypersecretion of mucus in patients from Iceland (Laufs et al., 2004). Two other research groups have reported the association of the genotype $\mathrm{GC}^{*} 1 \mathrm{~F}-1 \mathrm{~F}$ and the allele $\mathrm{GC}^{*} 1 \mathrm{~F}$ with COPD in Japan (Ishii et al., 2001; Ito et al., 2004). Similar results have been observed in China (Lu et al., 2004). It was shown that the genotype $\mathrm{GC}^{*} 2-2$ occurs less frequently among COPD patients than in the control group in Caucasians (1 versus 5\%) (Kueppers et al., 1977). Individuals bearing allele GC*2 are at a lower risk of COPD (Horne et al., 1990). Another study demonstrated the protective effect of genotype $\mathrm{GC}^{*} 2-2$ in 3\% patients and 14\% healthy controls (Schellenberg et al., 1998). The VDBP genotype frequencies do not show a difference between the groups with poor or normal lung function (Kauffmann et al., 1983). On the other hand, these results lack independent confirmation. As a powerful statistical method, meta-analysis is helpful to pool the results of individual studies and obtain a more precise estimate of the relationships among research themes (Ioannidis et al., 2001; Munafo, 2004). The purpose of our meta-analysis was to summarize independent studies (Horne et al., 1990; Schellenberg et al., 1998; Ishii et al., 2001; Ito et al., 2004; Laufs et al., 2004; Lu et al., 2004; Korytina et al., 2006; Janssens et al., 2010; Shen et al., 2010; Jung et al., 2014; Li et al., 2014) to arrive at some conclusions that may be helpful for clinical research on COPD. Genome-wide association studies (GWAS) are often used to identify SNPs associated with a disease but cannot always replicate the same result. In addition, GWAS can find out candidate SNP but do not involve calculation of an OR. Therefore, we did not include GWAS results.

We found a significantly increased risk of COPD associated with genotype GC*1F$1 \mathrm{~F}$ in all populations observed $(\mathrm{OR}=1.64,95 \% \mathrm{CI}=1.09-2.48, \mathrm{P}=0.02)$. Nevertheless, after stratification by ethnicity, significant risks were identified only in Asians $(\mathrm{OR}=1.73,95 \% \mathrm{CI}$ $=1.07-2.81, \mathrm{P}=0.03)$ but not in Caucasians $(\mathrm{OR}=1.44,95 \% \mathrm{CI}=0.57-3.66, \mathrm{P}=0.45)$. We found that the proportion of GC* $1 \mathrm{~F}-1 \mathrm{~F}$ was significantly higher in COPD group in Asians than that in Caucasians $(186 / 785=23.69 \%$ versus $29 / 625=4.64 \%)$. Meanwhile, a significant risk of COPD associated with allele $\mathrm{GC} * 1 \mathrm{~F}$ was observed in Asians $(\mathrm{OR}=1.35,95 \% \mathrm{CI}=1.04$ $1.75, \mathrm{P}=0.02)$ but not in Caucasians $(\mathrm{OR}=1.13,95 \% \mathrm{CI}=0.83-1.54, \mathrm{P}=0.43)$. These results revealed ethnic differences in the proportion of gene polymorphisms. Genotype GC*1F-1F or allele $\mathrm{GC}^{*} 1 \mathrm{~F}$ may be a potential candidate gene for screening of patients for COPD. It should be beneficial for individuals bearing GC* $1 \mathrm{~F}-1 \mathrm{~F}$ to undertake prophylaxis of COPD.

Our data show that there is no significant association of genotype GC*2-2 or allele 
GC*2 with COPD. This result is supported in theory by the studies of Schellenberg and Kasuga: Schellenberg concluded that VDBP genotypes cannot affect lung elastic recoil, upstream airway resistance, or neutrophil attraction (Schellenberg et al., 1998), and Kasuga stated that the VDBP variants are not associated with the damage to lung function in smokers (Kasuga et al., 2003). Our data also point to a protective effect of genotype GC*1F-1S and allele GC*1S in Asians; however, there is no significant association of genotypes Gc*1S-1S and GC*2-1S with COPD. This result may be due to the dominant trial of Korytina where Gc*1F-1S was considered a protective genotype. Because the sample size was not large, the results of this stratified analysis should be considered with caution.

To the best of our knowledge, to date there has been no meta-analysis testing the association of GC polymorphisms with COPD; thus, our meta-analysis may provide some data for further studies. On the other hand, a meta-analysis is limited by the quality and the volume of source studies, and may be unable to detect weak-to-moderate associations. Finally, many factors undoubtedly contribute to the development of COPD, including inherited and environmental factors as well as unknown factors.

\section{CONCLUSIONS}

VDBP has anti-inflammatory and immunomodulatory properties independent of vitamin $\mathrm{D}$ transport. This meta-analysis indicates that genotype $\mathrm{GC}^{*} 1 \mathrm{~F}-1 \mathrm{~F}$ or allele $\mathrm{GC} * 1 \mathrm{~F}$ is associated with a significantly increased susceptibility to COPD in Asians but not in Caucasians. No significant protective effect of genotype GC*2-2 against COPD is found in Asians and Caucasians. The protective effect of genotype GC*1F-1S and allele $\mathrm{GC}^{*} 1 \mathrm{~S}$ was observed in Asians but not in Caucasians. The VDBP gene polymorphism may be a promising marker for screening of patients for COPD.

\section{Conflicts of interest}

The authors declare no conflict of interest.

\section{ACKNOWLEDGMENTS}

The authors would like to thank Prof. Wim Janssens and Dr. Nele Heulens from KU Leuven for providing data and suggestions. Research supported by the National Natural Science Foundation of China (grant \#81273571) and by a project of Jiangsu Clinical Research Center for Respiratory Diseases (grant \#BL2012012).

\section{REFERENCES}

Agusti A, Edwards LD, Rennard SI, MacNee W, et al. (2012). Persistent systemic inflammation is associated with poor clinical outcomes in COPD: a novel phenotype. PLoS One 7: e37483.

Bakke PS, Zhu G, Gulsvik A, Kong X, et al. (2011). Candidate genes for COPD in two large data sets. Eur. Respir. J. 37 : 255-263.

Chishimba L, Thickett DR, Stockley RA and Wood AM (2010). The vitamin D axis in the lung: a key role for vitamin D-binding protein. Thorax 65: 456-462.

Cockayne DA, Cheng DT, Waschki B, Sridhar S, et al. (2012). Systemic biomarkers of neutrophilic inflammation, tissue injury and repair in COPD patients with differing levels of disease severity. PLoS One 7: e38629.

Devereux G, MacDonald H and Hawrylowicz C (2009). Vitamin D and asthma: time for intervention? Am. J. Respir. Crit. 
Care Med. 179: 739-740.

Eisner MD, Anthonisen N, Coultas D, Kuenzli N, et al. (2010). An official American Thoracic Society public policy statement: Novel risk factors and the global burden of chronic obstructive pulmonary disease. Am. J. Respir. Crit. Care Med. 182: 693-718.

Horne SL, Cockcroft DW and Dosman JA (1990). Possible protective effect against chronic obstructive airways disease by the GC2 allele. Hum. Hered. 40: 173-176.

Ioannidis JP, Ntzani EE, Trikalinos TA and Contopoulos-Ioannidis DG (2001). Replication validity of genetic association studies. Nat. Genet. 29: 306-309.

Ishii T, Keicho N, Teramoto S, Azuma A, et al. (2001). Association of Gc-globulin variation with susceptibility to COPD and diffuse panbronchiolitis. Eur. Respir. J. 18: 753-757.

Ito I, Nagai S, Hoshino Y, Muro S, et al. (2004). Risk and severity of COPD is associated with the group-specific component of serum globulin 1F allele. Chest 125: 63-70.

Jackson AS and Hopkonson NS (2011). Vitamin D in COPD - a pleiotropic micronutrient in a multisystem disease. Curr. Respir. Med. Rev. 7: 414-420.

Janssens W, Bouillon R, Claes B, Carremans C, et al. (2010). Vitamin D deficiency is highly prevalent in COPD and correlates with variants in the vitamin D-binding gene. Thorax 65: 215-220.

Jung JY, Choi DP, Won S, Lee Y, et al. (2014). Relationship of vitamin D binding protein polymorphisms and lung function in Korean chronic obstructive pulmonary disease. Yonsei Med. J. 55: 1318-1325.

Kasuga I, Pare PD, Ruan J, Connett JE, et al. (2003). Lack of association of group specific component haplotypes with lung function in smokers. Thorax 58: 790-793.

Kauffmann F, Kleisbauer JP, Cambon-De-Mouzon A, Mercier P, et al. (1983). Genetic markers in chronic airflow limitation: a genetic epidemiologic study. Am. Rev. Respir. Dis. 127: 263-269.

Korytina GF, Akhmadishima LZ, Yanbaeva DG and Victorova TV (2006). Genotypes of the vitamin-D-binding protein gene in patients with chronic obstructive pulmonary disease and in the healthy population of the republic Bashkortostan. Mol. Biol. 40: 200-206.

Kueppers F, Miller RD, Gordon H, Hepper NG, et al. (1977). Familial prevalence of chronic obstructive pulmonary disease in a matched pair study. Am. J. Med. 63: 337-342.

Lamprecht B, McBurnie MA, Vollmer WM, Gudmundsson G, et al. (2011). COPD in never smokers: results from the population-based burden of obstructive lung disease study. Chest 139: 752-763.

Laufs J, Andrason H, Sigvaldason A, Halapi E, et al. (2004). Association of vitamin D binding protein variants with chronic mucus hypersecretion in Iceland. Am. J. Phamacogenomics 4: 63-68.

Li XC, Liu XS, Xu YJ, Xiong WN, et al. (2014). The correlation of vitamin D level and vitamin D-binding protein gene polymorphism in chronic obstructive pulmonary disease. Chin. J. Intern. Med. 53: 303-307.

Lu M, Yang B and Cai YY (2004). The relationship between vitamin D binding protein gene polymorphism and chronic obstructive pulmonary disease. Zhonghua Nei Ke Za Zhi 43: 117-120. [In Chinese].

Mathers CD and Loncar D (2006). Projections of global mortality and burden of disease from 2002 to 2030. PLoS Med. 3: e442.

Munafo M (2004). Replication validity of genetic association studies of smoking behavior: what can meta-analytic techniques offer? Nicotine Tob. Res. 6: 381-382.

Rathored J, Sharma SK, Singh B, Banavaliker JN, et al. (2012). Risk and outcome of multidrug-resistant tuberculosis: vitamin D receptor polymorphisms and serum 25(OH)D. Int. J. Tuberc. Lung Dis. 16: 1522-1528.

Schellenberg D, Pare PD, Weir TD, Spinelli JJ, et al. (1998). Vitamin D binding protein variants and the risk of COPD. Am. J. Respir. Crit. Care Med. 157: 957-961.

Shen LH, Zhang XM, Su DJ, Yao SP, et al. (2010). Association of vitamin D binding protein variants with susceptibility to chronic obstructive pulmonary disease. J. Int. Med. Res. 38: 1093-1098.

Xue H, Su J, Sun K, Xie W, et al. (2012). Glutathione S-transferase M1 and T1 gene polymorphism and COPD risk in smokers: an updated analysis. Mol. Biol. Rep. 39: 5033-5042. 